\title{
Under complicated geological conditions of reservoir subdivision contrast
}

\author{
Weisong Yan \\ China's Heilongjiang province Daqing oilfield co. LTD. The fourth production plant Geological \\ brigade, China \\ yanweisong@petrochina.com.cn
}

Keywords: Segmentation contrast; Sedimentary characteristics, Overlap boundary, High resolution sequence stratigraphy.

\begin{abstract}
In this paper, application of high resolution sequence stratigraphy theory as the instruction, reconstruct the sedimentary system in the study area. And application of the results, The use of A1 block pattern encryption favorable opportunity, conditions for the development of reservoir in this block in the study adopt the cause of "standard under the well control move" contrast method, solve the problem "fence" layer belong Figure out the planar sedimentary microfiches in the block and the distribution characteristics of single sand bodies.
\end{abstract}

\section{Sequence stratigraphic classification and correlation}

Sequence stratigraphic division is the core technology of high resolution sequence stratigraphy method, compared with the traditional small layers compared to pay attention to the formation of cyclist character description, sequence comparison pay attention to the dynamic cause of cycle, due to the use of the concept of base level and base level cycle, always accompanied by the depositional cycle in the stratigraphic correlation analysis of the causes.

\section{2. "the cause of the standard under the well control moving boundary" method solve the problem of "the fence" layer belong}

Using the traditional "cycle comparison, classification control, different faces belt to discriminate" contrast method under the condition of the complex depositional more practical, but more than A1 block plane distributary channel is not deposited at the same time, phase differences, "cycle" correspondence between the two wells, "fence" layer. "Fence" layer is the contrast of the difficulty, is also the most prone to "interpose" place, Layer a partial struck first unit, a lower row to the next unit, caused the same single sand body in different well point into two cells. For example: according to the traditional method "Cycle correlation, Hierarchical control, Different faces belt " Comparison of well 1-4 even section (figure 1), Well 5-8 straight section (figure 2), look from the respective section division is very reasonable, but well P3 unit of 3, 4 wells and well P2 unit of 7, 8 wells is the same on the profile of single sand body, appear phenomenon like "scurrying layer", two cell is drawn to the same channel ,each unit is not a complete channel, in sedimentary microfiches in the plane figure appeared the contradiction of "passive river" ,adopt the cause of "standard under the well control move" method effectively solved the problem ,the contrast threshold set in the middle of the sand body temporarily, rather than the contrast threshold directly on the top or bottom of sand body. After the block uniform contrast, the channel sand body back in the source direction, in accordance with the unified sand body cause the contrast threshold adjustment, ensure the accuracy of the division of time units. 


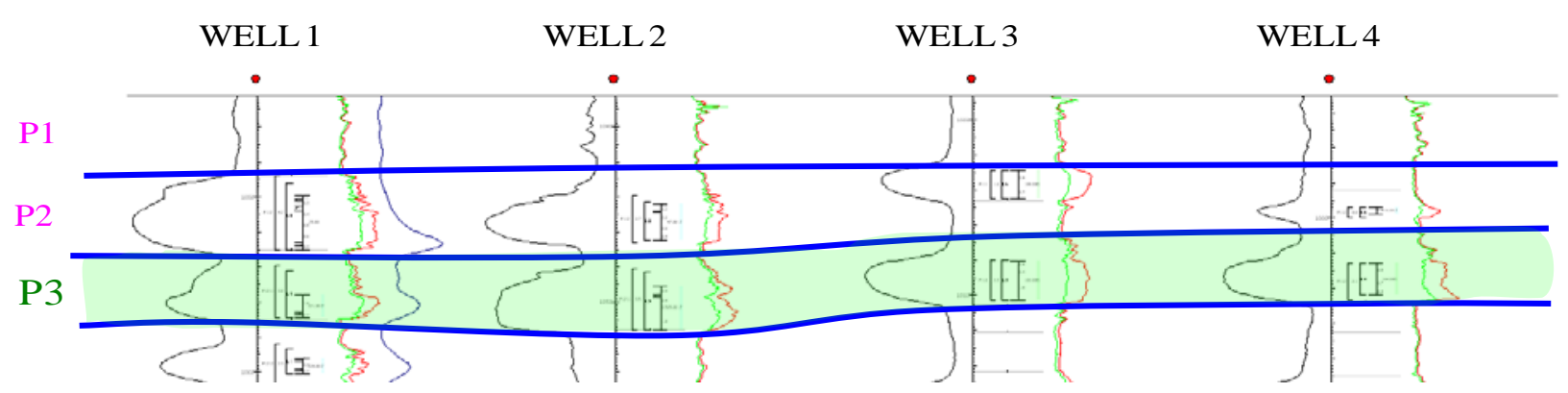

Figure 1 well 1-4 Wells even well section

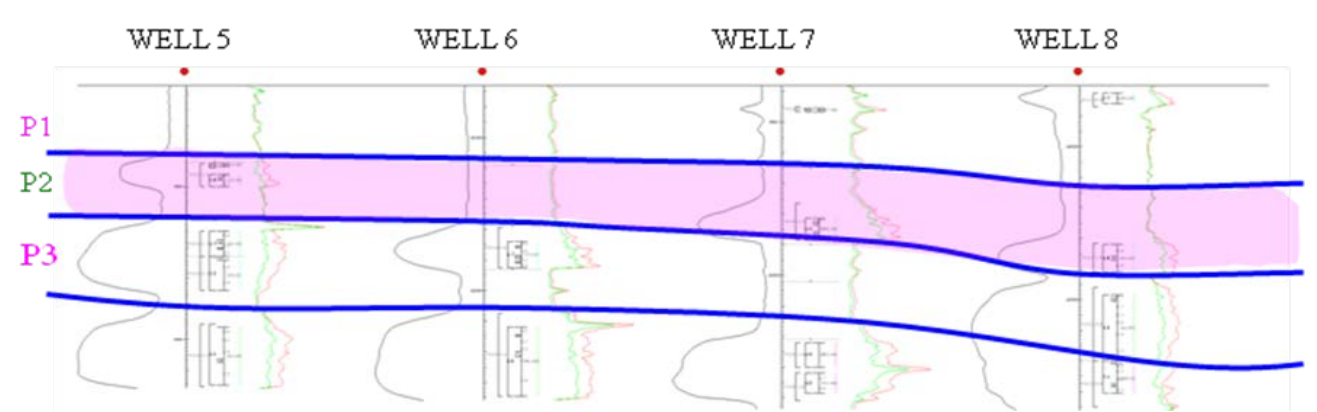

Figure 2 Figure 1 well 5-8 Wells even well section

\section{The sedimentary characteristics and the causes of $\mathbf{P} 2$ unit in the region}

A1 block P2 unit formation thickness is small, 58.2\% of the well point only a sedimentary cycle and horizon is not stable, do not have divided two units of geological conditions. This seems to contradict of sedimentary system between the results (The P2 unit period development two cells are in the cover up and down). Through comprehensive research: The P2 unit sedimentary period of the ancient terrain is high, The tectonic subsidence rate is less than the sediment supply rate and form a sedimentary cycle, Belong to the continuous deposition, the cycle of the up and down unit have in common.

\section{P3 units overlap boundary determined}

P3 units in A1 block exposed overlap boundary, Causing some well point development 6 units, Some of the well point development 7 units, Greatly increasing the difficulty of segmentation contrast, is the difficulty and key point of this research. In the process of the contrast, the application of high resolution sequence stratigraphy theory fully, The dynamic causes of analysis exposed the line, Research shows that: The ancient topography is to control the P I 3 unit overlap boundary of the main factors, And the ancient terrain east west high low, low tectonic framework from north to south, Nature of the two different form from east-west and south-north exposed line (figure 3).

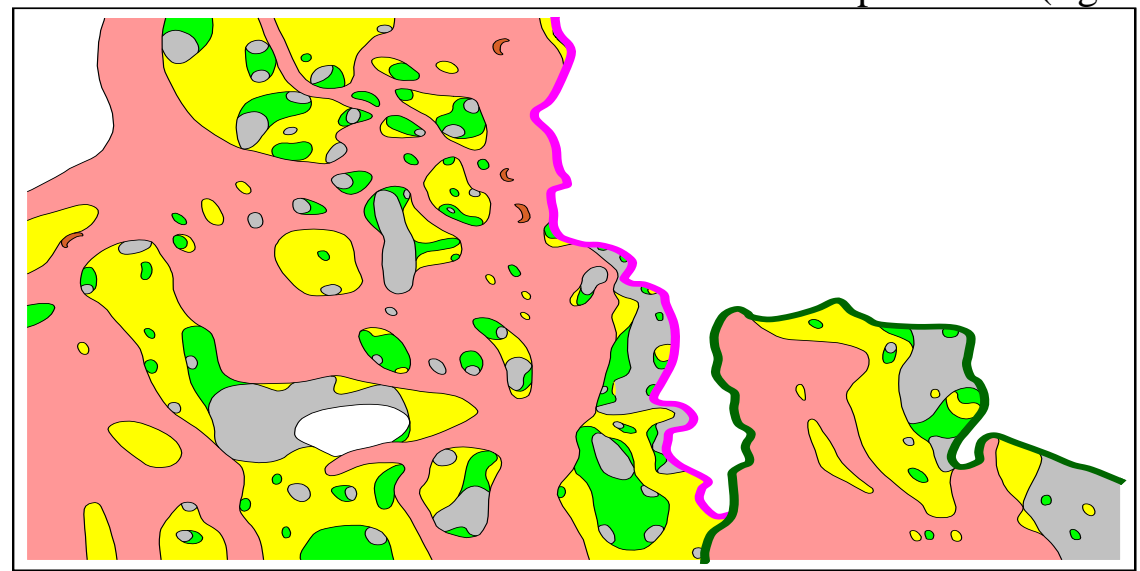

Figure 3 A1 block unit P3 plane sedimentary faces belt graph and two out of the line 
North and south to the line: the DEW line controlled by the east west high low ancient terrain, extending direction for north and south. On the west side near the line development a nearly north-south river, About $1100 \mathrm{M}$ wide, thick 3.6M. The river is P3 unit can swing from west to east and completely preserved last one channel, also determines the location of exposed line.

East and west to the line: The dew line was mainly affected by meteorological terrain north low, At the same time by the ancient topography east west high low, and the fault, At the same time the ancient terrain east west high low position control and fault, the ancient river sedimentary, Extension is in the north west - south east, north of the ancient terrain is high, Located in the sedimentary base level above, no hold the space, Rivers carry sediment passing leave ,Eventually the overlap boundary.

\section{Conclusion}

In this paper, on the basis of the theory of high-resolution sequence stratigraphy, A1 block for the sequence division and correlation, the study on the solution under the condition of the complex depositional long-standing dispute. Accurate segmentation compared various depositional time unit and the map of sedimentary faces belt, and obtained the following new understanding:

(1) the P2 units fully developed on A1 blocks, Because of high ancient terrain, tectonic subsidence rate is less than the sediment supply rate, P21 and P22 units continuous deposition and form a sedimentary cycle, The cycle of the up and down unit have in common. This is also causes the original error objective factors.

(2) Determine the P3 units in A1 blocks overlap boundary, the ancient topography is the main factor controlling overlap boundary, and ancient terrain east west high low, low tectonic framework from north to south, two nature formed from east-west and south-north different out of the line.

\section{6. references}

[1] shi-zhong ma, River delta system in song Liao basin of high resolution sequence stratigraphy, reservoir configuration and heterogeneous model research [D]. Chinese academy of sciences, institute of geology and geophysics, (2003), p.232-238.

[2] xiao-guang lv, Hong-wen Yu ,Dong-hui Tian, etc. The late high water cut oilfield subdivision of the single sand layer geological research [J]. Xinjiang petroleum geology,1993, 14(4), p. 345 349.

[3]Hanqing Zhao, Zhiguo Fu, Xiaoguang Lv, etc. A large rivers delta sedimentary reservoir fine description method [J]. Journal of oil, 2000, 21 (4), p.109 113. 